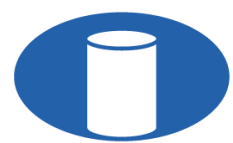

IBRACON

ORIGINAL ARTICLE

\title{
Fracture bi-linear model parameters and brittleness of high- performance concretes for paving: why fatigue tests matters and cannot be spared?
}

\section{Parâmetros do modelo bilinear de fratura e fragilidade de concretos de alto desempenho para pavimentação: por que estudos de fadiga interessam e não podem ser dispensados?}

\author{
José Tadeu Balbo ${ }^{a}$ \\ Andrea Arantes Severi ${ }^{\mathrm{b}}$ (D) \\ Tatiana Cureau Cervo ${ }^{c}$ \\ Andréia Posser Cargnin ${ }^{\mathrm{a}}$ (D)
}

\section{aUniversidade de São Paulo - USP, Escola Politécnica, Departamento de Engenharia de Transportes, Laboratório de Mecânica de Pavimentos - LMP, São Paulo, SP, Brasil \\ ${ }^{\text {b} E c o w o r l d, ~ S a ̃ o ~ P a u l o, ~ S P, ~ B r a s i l ~}$ \\ ${ }^{c}$ Universidade Federal de Santa Maria - UFSM, Centro de Tecnologia, Departamento de Transportes, Grupo de Estudos e Pesquisas em Pavimentação e Segurança Viária - GEPASV, Santa Maria, RS, Brasil}

Received 24 April 2018

Accepted 14 May 2020

\begin{abstract}
Fracture tests on two high-performance concrete for pavements were performed using the wedgesplit test. The results allowed perceiving the same specific fracture energy for both concrete. However, the crack opening during the tests as well as the characteristic length of the materials resulted in roundly distinct behaviors in terms of brittleness. Previous fatigue studies for both concretes are then fairly readdressed pointing out the unavoidable needs for studying the concrete brittleness as a parametric way for selecting suitable concrete proportions and materials as well as to reach its microstructural behavior in order to acquire an appropriate judgment about its fatigue performance.
\end{abstract}

Keywords: concrete, fracture, fatigue, brittleness.

Resumo: Estudos de fratura sobre dois concretos de alto desempenho para pavimentação foram realizados empregando-se o wedge-split test. Com base nos ensaios foi possível observar que a energia de fratura específica era semelhante para ambos os concretos estudados. Na realidade, apenas a medida de taxa de abertura de fissuras durante os ensaios, bem como a determinação do comprimento característico e o número de fragilidade dos materiais permitiu a sua diferenciação com clareza, apontando a relevante fragilidade de um concreto em relação ao outro. Estudos anteriores de fadiga para ambos os concretos são revisitados, permitindo concluir pela necessidade da caracterização da fragilidade de concretos como meio paramétrico de seleção de dosagens, bem como para o correto entendimento de sua microestrutura que resulta em seu comportamento à fadiga.

Palavras-chave: concreto, fratura, fadiga, fragilidade.

How to cite: J. T. Balbo, A. A. Severi, T. C. Cervo, and A. P. Cargnin, "Fracture bi-linear model parameters and brittleness of high-performance concretes for paving: why fatigue tests matters and cannot be spared?," Rev. IBRACON Estrut. Mater., vol. 14, no. 1, e14101, 2021, https://doi.org/10.1590/S1983-41952021000100001 


\section{INTRODUCTION}

\subsection{Background and motivation}

In 2015, during the discussion of a doctorate thesis at the University of Delft [1] which included several fatigue tests on cementitious design mixtures for pavement bases, one member of the board (American university professor) asked the candidate why not perform fracture tests to decide about the material mixture design and about its durability potential in the field in clear opposition to the time-consuming and costly flexural fatigue tests [2].

Considering this frequent thinking, this study presents fracture tests for two concrete types, which are similar to ones previously studied [3]. So, this paper brings up this old discussion, seeking to point out the ability of some parameters to, indeed, distinguish the utility of these tests in a comparative and complementary way considering the concrete pavements issues. For this purpose, fracture tests parameters for identical specimens of two concretes are presented, addressed and compared to fatigue tests carried out on the same concretes, in order to indicate their value to make it clear the different fatigue behavior of such materials and in the case of Pavement Mechanics, especially for pavement structural designers, regarding the current normative context whether Brazilian, American or European.

\subsection{Fracture Energy Concept and the Crack Coalescence}

The specific fracture energy $\left(\mathrm{G}_{f}\right)$ is a parameter of paramount relevance to the characterization of fractured structures and it is affected by the specimen size used for its measurement [4]; in other words, there is a scale factor continuously influencing the results. There are specific recommendations from RILEM [5], for instance, for computing this energy: The full fracture work shall be divided by the fractured area (the area originally without notches), and the test formats commonly used are prismatic samples with a central notch and vertical load over its surface in the same direction of the notch; or using methods of splitting by a wedge forcing the crack under the notched area (using cubic or cylindrical samples). The specific fracture energy, given by the load-displacement or load-crack opening curves is defined by Equation 1:

$$
G_{f}=\frac{1}{\mathrm{~A}} \int_{0}^{\delta_{\mathrm{utt}}} \mathrm{F}_{\mathrm{H}} \cdot \mathrm{d} \delta
$$

where $\mathrm{A}$ is the area under fracture during the test, $\mathrm{F}_{H}$ is the horizontal force (in the wedge test over cubes, for instance), $\delta$ is the displacement and $\delta_{u l t}$ is the final displacement during the test when $\mathrm{F}_{H}=0$. It is convenient to remark that the force-displacement curve for $\mathrm{G}_{f}$ calculation is taken from the force peak, when the relaxation and catastrophic regimen starts [6], inducing the crack propagation within the entire area of the sample. The zone between the zero initial force and the peak is admitted, for practical purposes, as the elastic zone where there is no material plastification. The size of the tested specimen does not seem to be a worthless geometric aspect in the fracture analysis (elastic-linear fracture mechanics) as stated by several authors [7].

The fracture tests for road materials analysis and mixture design, especially brittle materials, such as concretes and bases as cement treated crushed stones and roller compacted concretes, although rarely used, has the great advantage of allowing the prediction of the material behavior from the strain's approach (microstructural).

In fracture toughness tests, at the same concrete beam is notched causing a vertical flat section with a height lower than all the others vertical sections of the sample; the vertical loading is applied on the same direction of the notch, in such a way that the stress lines are concentrated in the notch tip, making the sample starts cracking in this zone, forcing the fracture always in that vertical plan or very close to it (Figure 1). That should reduce or even eliminate the test dispersion, avoiding the fracture zones randomness like in fatigue tests. Rots et al. [8] state that as the deformation position in the fracture zone is defined, the surrounding zone unloaded, which means the micro-cracking in the surrounding area is captured or even blocked.

Nevertheless, the authors recommend five to ten tests that should be run to calculate the mean fracture toughness parameters (for example, Karihaloo et al. [4]).

The elastic energy stored in the specimen tested is proportional to the material volume, whereas the fracture energy is related to the fracture area [9]. So, the relation between both suggests a characteristic linear length which distinguishes them, namely characteristic length $\left(\mathrm{I}_{c h}\right)$, as shown in Equation 2: 


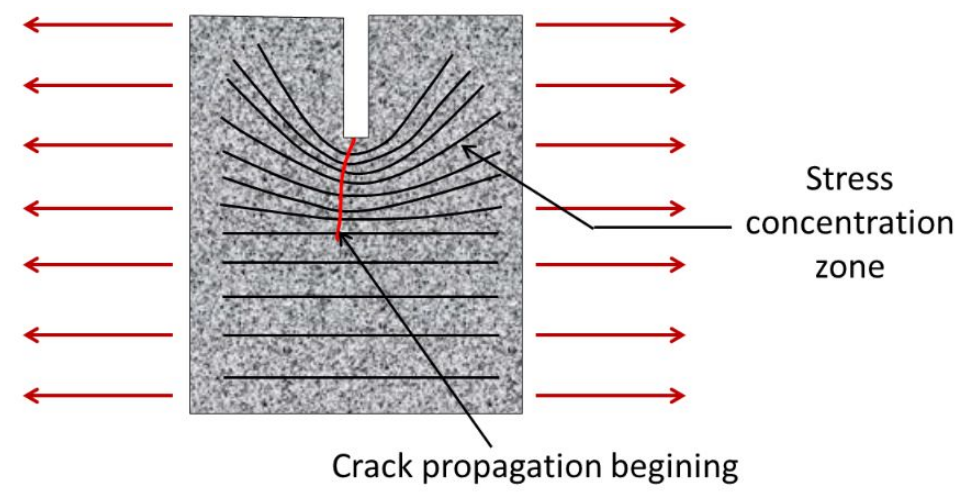

Figure 1. Stress concentration in the notch tip of cubic concrete specimens (adapted from Balbo, 2009).

$I_{c h}=\frac{G_{f} \times E}{f_{t}^{2}}$

where $E$ is the material elastic-linear modulus of elasticity, $\mathrm{f}_{t}$ is the tensile strength and $\mathrm{G}_{f}$ is the specific fracture energy. The brittleness of a certain material is reduced for longer characteristic lengths [10], 11], allowing material comparisons regarding this parameter. Equation 3 defines the brittleness number, which is proportional to the characteristic length $(L)$ and is related to the material tensile strength $\left(\mathrm{f}_{t}\right)$, its modulus of elasticity $(E)$ and specific fracture energy $\left(\mathrm{G}_{f}\right)$ as well:

$B=\frac{f_{t}^{2} \times L}{G_{f} \times E}$

Considering the two concretes for pavements assessed in this paper, which were also studied by Cervo [12] and Cervo and Balbo [3] under the fatigue approach, it was observed that the high strength concrete (HSC) (with high cement consumption and micro-silica addition, with a smaller maximum aggregate size) fails under lower fatigue cycles. However, due to the reasons aforementioned, and the fatigue response during the tests, microstructural parameters such as energy, fracture deformation and brittleness are not obtained directly, hindering the objective interpretation of such parameters. So, in this paper, the same concrete mixes former studied regarding their fatigue behavior, are studied seeking to make it clearer their behavior in the light of the most important fracture parameters. Finally, the concretes are compared by the cohesive zone model, using the graphic approach proposed by Petersson [13].

\subsection{The Fatigue Strength concepts and the Crack Coalescence}

Traditional fatigue tests on pavement materials are usually performed on beams by the third-point beam tests (flexural) and present great results dispersion, at most, due to the randomness of the fracture planes; the flexural stresses cause gradual microstructural breaks, but following random planes since in the middle third the bending moment is constant, making the crack coalescence starts in the weaker planes following through the surrounding zones where the crack progress is facilitated point to point. It means that each sample tested has a specific fracture geometry which usually does not follow a planar state, in contrast to what normally happens in fracture tests.

An explanation [14] to fatigue behavior can be "is a phenomenon or process of damaging or deteriorating the mechanical characteristics of certain materials causing its failures as a structural component. Consequently, fatigue is a behavior change sign, in other words, it is the material failure over an initial pattern; this change is harmful and sometimes catastrophic. As the fatigue process goes forward there is the crack coalescence in the material microstructure and when the crack length is longer than the namely critical length, the material breaks. It happens under cyclic loadings when the strains experienced by the material are slower than its strain capacity; therefore, it cannot be confused with a static strength rupture." 
Considering $\mathrm{N}_{f}$ as the number the loading cycles until failure (crack) and $2 \mathrm{~N}_{f}$ the reversal number during the test to happen the same failure, the strain elastic component is given by Equation 4 :

$$
\frac{\Delta}{2}=\frac{\sigma_{a}}{E}=\left(\frac{\sigma_{f}^{\prime}}{E}\right) \cdot\left(2 N_{f}\right)^{b}
$$

where $\Delta \varepsilon / 2$ is the elastic strain amplitude, $\sigma_{f}^{\prime}$ is the stress coefficient or stress at $2 N_{f}=1$ cycle, E is the material modulus of elasticity and $\mathrm{b}$ is an experimental coefficient, namely fatigue strength coefficient, normally admitted as linear in the $\log -\log$ representation, where $b$ is the slope of the fatigue curve obtained through the tested specimens ( $\varepsilon$ as a function of $\mathrm{N}_{f}$ ).

Regarding the plastic component $\left(\varepsilon_{p}\right)$, it is expressed by Equation 5:

$$
\frac{\Delta \varepsilon_{p}}{2}=\frac{\sigma_{a}}{E}=\varepsilon_{f}^{\prime} \cdot\left(2 N_{f}\right)^{c}
$$

where $\varepsilon_{f}^{\prime}$ is the ductility coefficient, equivalent to the plastic strain for $2 \mathrm{~N}_{f}=1$ cycle and $\mathrm{c}$ is the fatigue ductility exponent (Figure 2). The lower the $\mathrm{c}$ value, the greater the fatigue ductility of the material studied, i.e., the lower its brittleness, breaking under plastic strain higher levels.

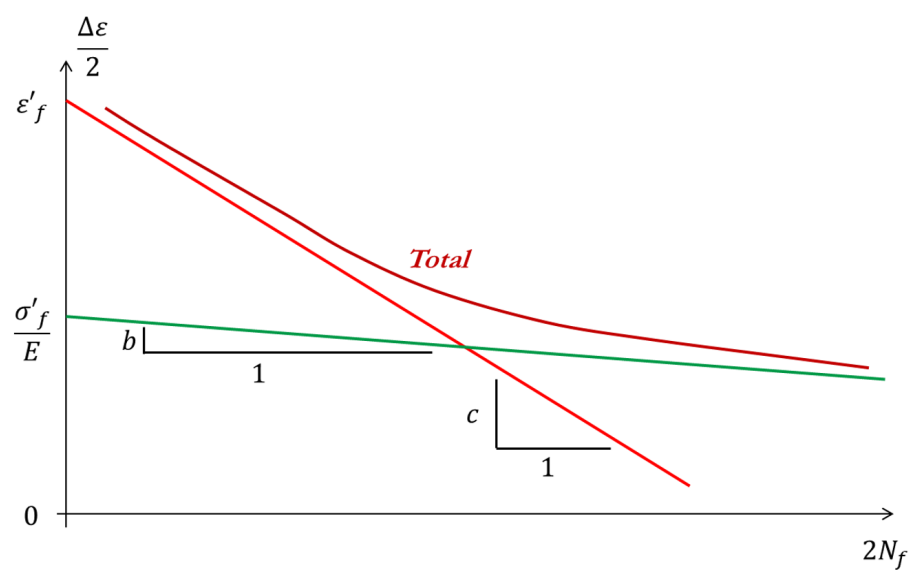

Figure 2. Elasto-plastic components fatigue behavior (Adapted from Balbo, 2009).

Fatigue flexural tests with concrete beams are usually described by statistic models or transfer functions which relate the flexural stress applied $\left(\sigma_{t f}\right)$, the flexural concrete strength $\left(f_{c t, f}\right)$ and the fatigue strength $\left(N_{f}\right)$, through the "S-N" curves, as presented in Equation 6 for tests conducted under controlled stress, with a and b called experimental coefficients.

$\log _{10} N_{f}=a+b \cdot\left(\frac{\sigma_{t f}}{f_{c t, f}}\right)$

\section{EXPERIMENTAL METHOD FOR FRACTURE STUDIES}

In order to assess the specimen's fracture on Mode I (pure tensile), the wedge splitting test was conducted with cubic concrete specimens of $150 \times 150 \times 150 \mathrm{~mm}^{3}$. Ten identical specimens from the same concrete batching produced 
in the lab were prepared for each concrete (Table 1). The wedge splitting test requires the use of cubic specimens with a size of $150 \mathrm{~mm}$, which must be notched.

Table 1. Materials employed and concrete characteristics

\begin{tabular}{ccc}
\hline Materials and characteristics & Conventional concrete & High strength concrete \\
\hline Cement consumption $\left(\mathrm{kg} / \mathrm{m}^{3}\right)$ & 396 & 420 \\
\hline Cement type & $\mathrm{CP} \mathrm{II} \mathrm{32}$ & $\mathrm{CP} \mathrm{V}$ \\
\hline Coarse aggregate $19 \mathrm{~mm}\left(\mathrm{~kg} / \mathrm{m}^{3}\right)$ & 483 & - \\
\hline Coarse aggregate $25 \mathrm{~mm}\left(\mathrm{~kg} / \mathrm{m}^{3}\right)$ & 724 & 641 \\
\hline Fine aggregate - medium sand $\left(\mathrm{kg} / \mathrm{m}^{3}\right)$ & 620 & 204 \\
\hline Water $\left(\mathrm{L} / \mathrm{m}^{3}\right)$ & 180 & 1.428 \\
\hline Plasticizer $\left(\mathrm{L} / \mathrm{m}^{3}\right)$ & 1.388 & 2.38 \\
\hline Superplasticizer $\left(\mathrm{L} / \mathrm{m}^{3}\right)$ & - & 42 \\
\hline Silica fume $\left(\mathrm{kg} / \mathrm{m}^{3}\right)$ & - & 0.442 \\
\hline Water/cement ratio & 0.455 & 22.6 \\
\hline Compressive strength $(\mathrm{MPa})-24$ hours & - & 35.1 \\
\hline Compressive strength $(\mathrm{MPa})-7$ days & - & 53.2 \\
\hline Compressive strength $(\mathrm{MPa})-28$ days & 37.6 & 3.5 \\
\hline Flexural strength $(\mathrm{MPa})-24$ hours & - & 76.7 \\
\hline Compressive strength $(\mathrm{MPa})-110$ days & 48.0 & 3.5 \\
\hline Flexural strength $(\mathrm{MPa})-24$ hours & - & 7.0 \\
\hline Flexural strength $(\mathrm{MPa})-7$ days & - & 7.2 \\
\hline Flexural strength $(\mathrm{MPa})-28$ days & 5.14 & 5.3 \\
\hline Indirect tensile strength $(\mathrm{estimated}-\mathrm{MPa})$ & 4.0 & $38,000(29$ days $)$ \\
\hline Modulus of Elasticity $-\mathrm{E}(\mathrm{MPa})$ & $32,000(55$ days $)$ & $42,900(100$ days $)$ \\
\hline Modulus - E (MPa) - fracture tests & $36,200(100$ days $)$ &
\end{tabular}

Figure 3 depicts the schematic representation employed for type I fracture tests through the wedge splitting test; on the top of the concrete cube is made a notch (concrete is cutout) along the specimen length. On this wide upper notch are positioned two metallic segments along the specimen length; such segments have two downright faces that are thoroughly fitted to the lateral and bottom surfaces of the notch. Then a wedge is introduced between those metallic segment's diagonal faces, slipping on small metal cylinders. As the applied vertical force on the wedge increases, horizontal deformations trend to separate both sides of the specimen, resulting in its fracture underneath the thin vertical notch below the top wide notch [15].

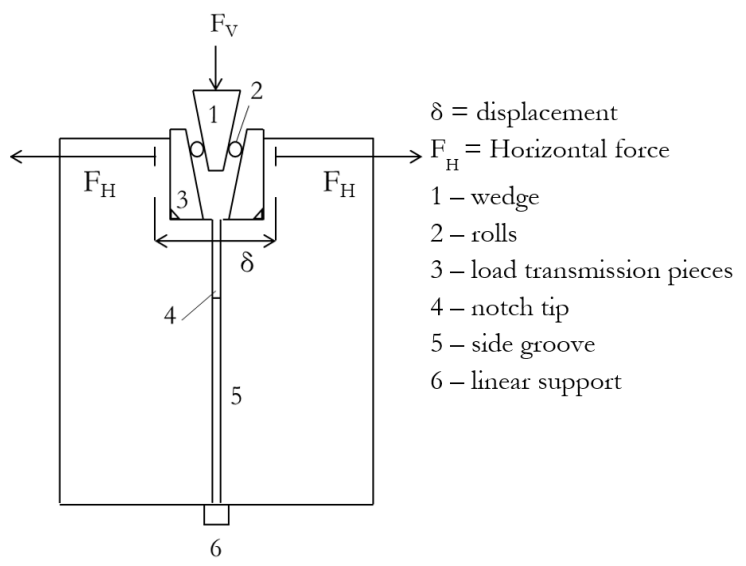

Figure 3. Test arrangement: fracture zone between points 4 and 6 ; horizontal pieces for application wedge with devices 1 and 3 ; 5 represents the height of the face initially linked.

Figure 4 details the test arrangement and the specimen positioned to be tested. The machine employed is a universal Hydropulse test adjusted for static constant load application; tests were conducted at $0.4 \mathrm{kN} / \mathrm{s}$. Two Linear Variable 
Differential Transformer (LVDT) were installed at the top of the device arrangement on the concrete cube in order to measure displacements while the wedge moves entering the large superior notch when force actuates; both LVDT are placed in opposed faces and oppositely at surface extremities, but at the same horizontal plane (see Figure 4 top).
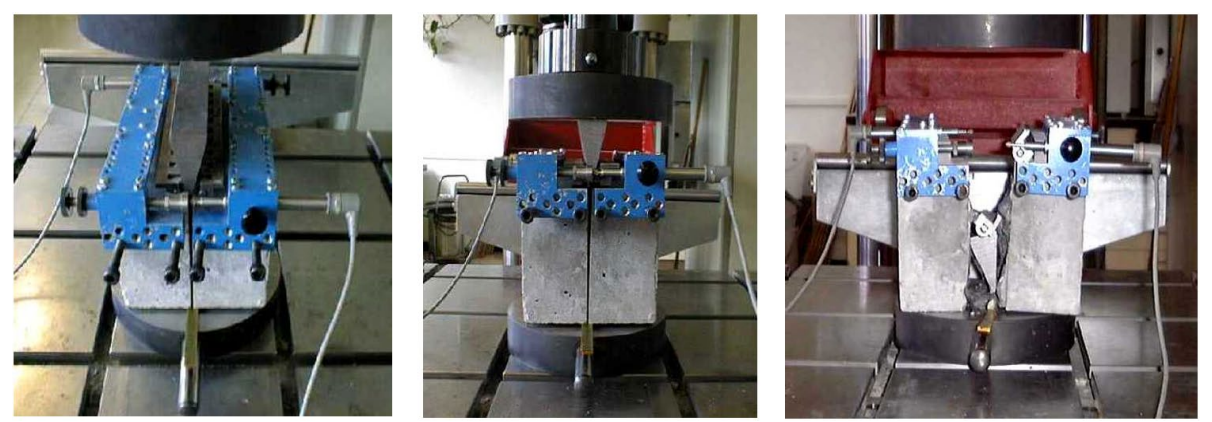

Figure 4. Test arrangement: at left the wedge is seen in the whole concrete cube extension; at the center it is seen the vertical notch; at right it is seen the fractured concrete cube.

At last, Figure 5 illustrates the cuts and notches made in the cubic specimen and the linking zone before the test. Figure 6 shows the fractured faces for conventional concrete and the HSC for two cubes after the test; the images make it clear the different maximum diameters of aggregates for the two concrete mixtures.

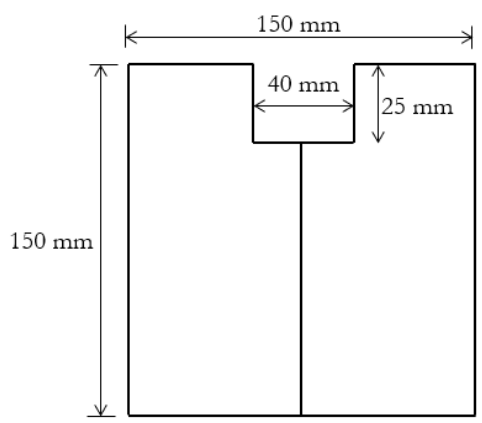

Front view

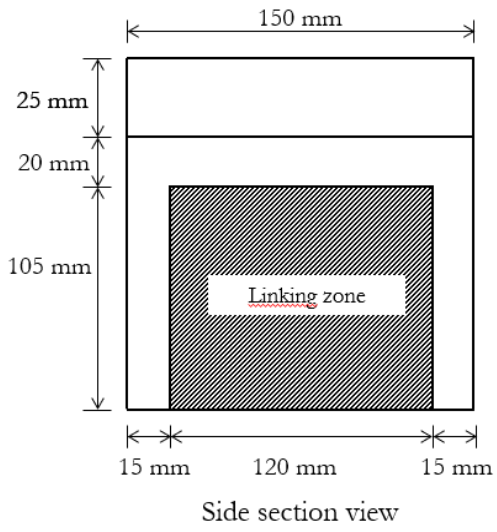

Figure 5. Cut zones sizes at the concrete cube (notches).

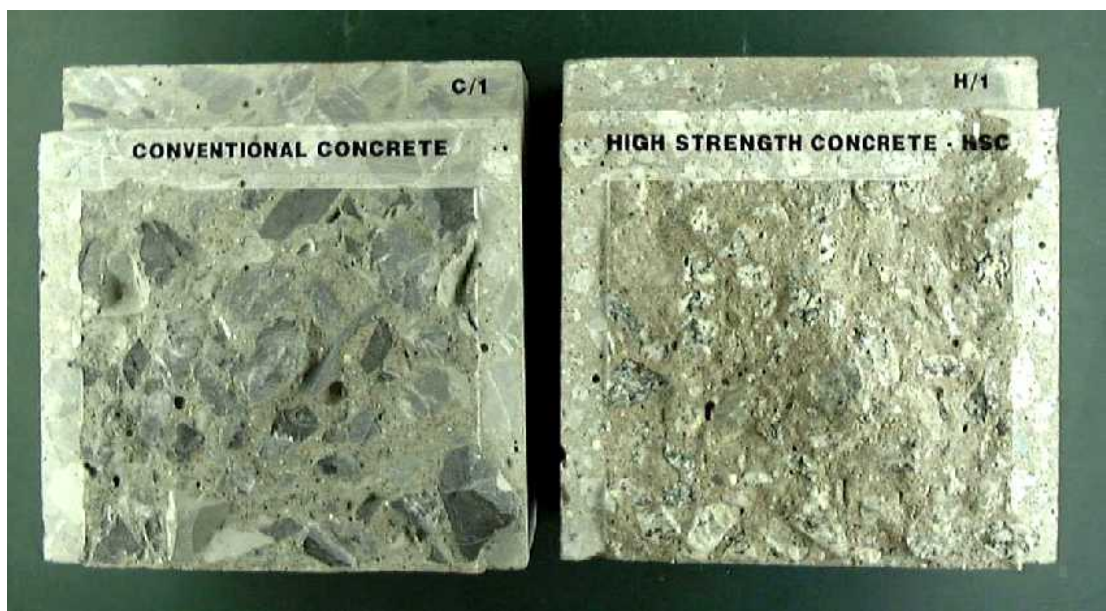

Figure 6. Conventional concrete (left) and high strength concrete (right) fractured faces. 
Tests on the modulus of elasticity for both the conventional and HSC mixes were performed to determine the fracture parameters. Therefore, following to the fracture tests, cylindrical specimens with $50 \mathrm{~mm}$ of diameter were cored from both non-fractured sizes of the specimens to measure the compressive modulus of elasticity; it is an approximate value related to the concrete flexural modulus of elasticity and differences around $10 \%$ are recorded for both tests [16]. The fracture tests were performed at the ages of 97 and 95 days for conventional concrete and 84 and 92 days for the HSC. All these tests were held in the TFB (Technische und Forschung Beratungsstelle, Wildegg) facilities.

Modulus of elasticity was measured by simple arrangements of cylindrical specimens cored from the non-fractured parts of the concrete cubes $(50 \mathrm{~mm} \times 150 \mathrm{~mm})$, using uniaxial compression tests on a universal testing machine and employing LVDTs for measuring vertical strains during the tests, conducted at the same aforementioned rate of force application. This parameter in compression tests is commonly affected by aggregate type and size while the interfacial transition zone phase is critical for measuring the modulus of elasticity in tensile. Due to aggregate type (mineral structure and origin), for instance, multiplicative correction factors for modulus of elasticity measured over basalt and limestone aggregate are, respectively close to 0.90 and 1,20 [17]. One should note that the magmatic rocks tend to be harder and stiffer than some sedimentary ones; this study employed limestone aggregates for the conventional concrete and granitic aggregates for the high strength concrete, which contributes somehow to improve results for the high strength concrete.

Though the parameter is also affected by the maximum coarse aggregate size, complexity on establishing the degree of comparison among the different concretes where really affected not only by the own aggregate model phase of a multiphase material but also by the sharp differences on the paste-mortar phases of both concrete mixes: (1) high strength concrete using $66 \mathrm{~kg} / \mathrm{m}^{3}$ in excess of different nature of hydraulic binders (including $40 \mathrm{~kg} / \mathrm{m}^{3}$ of highly fine silica fume); (2) conventional concrete employing $1,207 \mathrm{~kg} / \mathrm{m}^{3}$ of coarse aggregates (a blend of $19 \mathrm{~mm}$ and $25 \mathrm{~mm}$ diameters), i.e., circa $200 \mathrm{~kg} / \mathrm{m}^{3}$ in excess than the high strength concrete. If now one considers that the compressive strength at 100 days is circa $63 \%$ greater for the HSC and its modulus of elasticity is $84 \%$ greater, the issue of maximum diameter becomes a little bit hard to discuss, if one expects higher compressive moduli when higher diameters are presented. Therefore, the bottom line of the discussion to be done is whether fracture or fatigue parameters are able to explain the mixtures' performances in macro and microstructural points of view. Fracture tests will suggest very different concrete performances as suggested from former fatigue studies for the mixtures?

\section{RESULTS}

Table 2 presents the average results obtained for ten tests for each concrete, for a parameter such as the critical load applied, the crack width, the fracture energy, and the specific fracture energy. The load when the fracture starts (peak) is higher for the HSC than the conventional concrete; note that when this force occurs the notched width is the same for both concretes and it is about five-hundredths of a millimeter (Figure 7 and 8). However, when the maximum dissipated energy is reached, although the energies are similar for both the concrete (see $\mathrm{G} f$ in Figures 9 and 10), the crack width in the conventional concrete notch is twice the crack width in the HSC denoting the greater brittleness of the HSC.

Table 2. Fracture test parameters, crack length and energy

\begin{tabular}{|c|c|c|c|c|c|c|c|c|c|c|}
\hline \multirow[b]{2}{*}{ Type } & \multirow[b]{2}{*}{ Value } & \multicolumn{3}{|c|}{ Dimensions } & \multicolumn{2}{|c|}{ At maximum force } & \multicolumn{3}{|c|}{ At maximum energy } & \multirow[b]{2}{*}{$G_{f}(\mathbf{N} / \mathbf{m})$} \\
\hline & & $\mathbf{L}(\mathbf{m m})$ & $\mathbf{H}(\mathbf{m m})$ & $\begin{array}{c}\text { Area } \\
\left(\mathbf{m}^{2}\right)\end{array}$ & $\begin{array}{c}\text { Force } \\
(\mathbf{k N})\end{array}$ & $\begin{array}{l}\text { Crack } \\
\text { width } \\
(\mathrm{mm}) \\
\end{array}$ & $\begin{array}{c}\text { Force } \\
(\mathbf{k N})\end{array}$ & $\begin{array}{l}\text { Crack } \\
\text { width } \\
(\mathrm{mm}) \\
\end{array}$ & $\begin{array}{c}\text { Fracture } \\
\text { energy } \\
(\mathbf{N} / \mathbf{m}) \\
\end{array}$ & \\
\hline & Mean & 128.5 & 114.3 & 0.015 & 5.571 & 0.044 & 0.019 & 3.380 & 1.45 & 97.91 \\
\hline \multirow[t]{3}{*}{$\mathrm{CV}$} & $\mathrm{SD}$ & 8.0 & 5.5 & 0.001 & 0.670 & 0.003 & 0.009 & 1.455 & 0.41 & 21.09 \\
\hline & $\mathrm{CoV}(\%)$ & 6.2 & 4.8 & 7.025 & 12.030 & 7.528 & 45.829 & 43.054 & 27.91 & 21.54 \\
\hline & Mean & 126.9 & 112.7 & 0.014 & 7.780 & 0.046 & 0.026 & 1.672 & 1.39 & 97.39 \\
\hline \multirow[t]{2}{*}{ HSC } & SD & 2.6 & 1.2 & 0.000 & 0.608 & 0.003 & 0.011 & 0.334 & 0.16 & 12.71 \\
\hline & $\mathrm{CoV}(\%)$ & 2.0 & 1.1 & 2.138 & 7.816 & 5.619 & 43.020 & 19.982 & 11.83 & 13.05 \\
\hline
\end{tabular}

Figures 7 and 8 show the curves force versus strain (crack width) for both conventional and HS concretes. The graphs detail the differences between the peak forces for the crack coalescence beginning and the crack width at the 
end of the test, as well. These are the highlighted differences between the set of tests conducted since there is not much difference in the total energy where the areas are compensated regarding the curvature for crack width around $0.5 \mathrm{~mm}$.

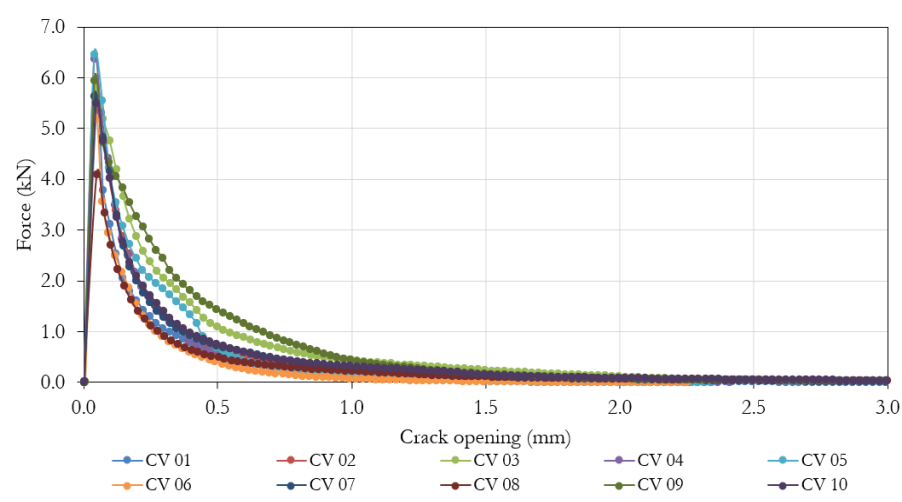

Figure 7. Force versus crack width curves for conventional concrete.

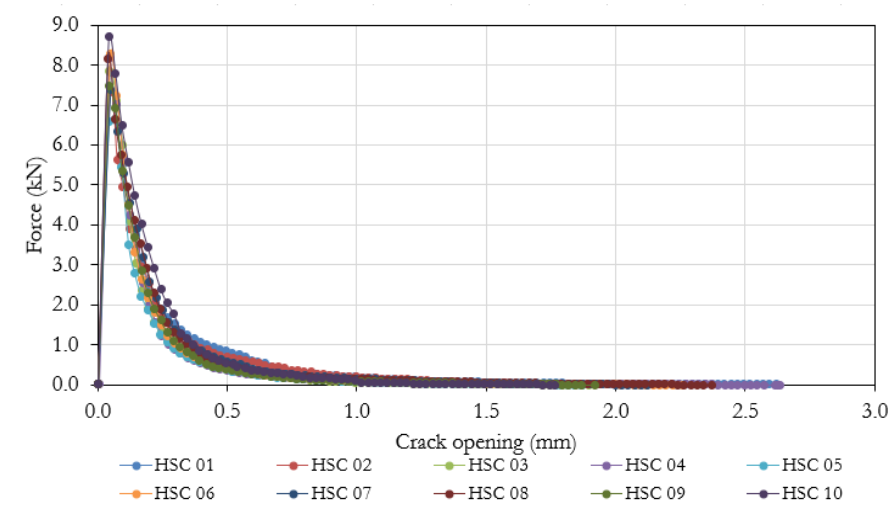

Figure 8. Force versus crack width curves for the high strength concrete.

In Figure 7 is worth noting to remember that specimen CV5 presented some unstable post-peak behavior. During the discussion with the lab technicians it was clarified that in face of daily fracture tests performed at TFB and considering that the other 19 tests for this study with no signals regarding instability, possible small and non-detected displacement of the testing table was imputed for such a specific misbehavior, though not affecting the fully coherence of the CV5 test. There is no reason for the possible failure to be omitted or discharged on the results in Figure 7.

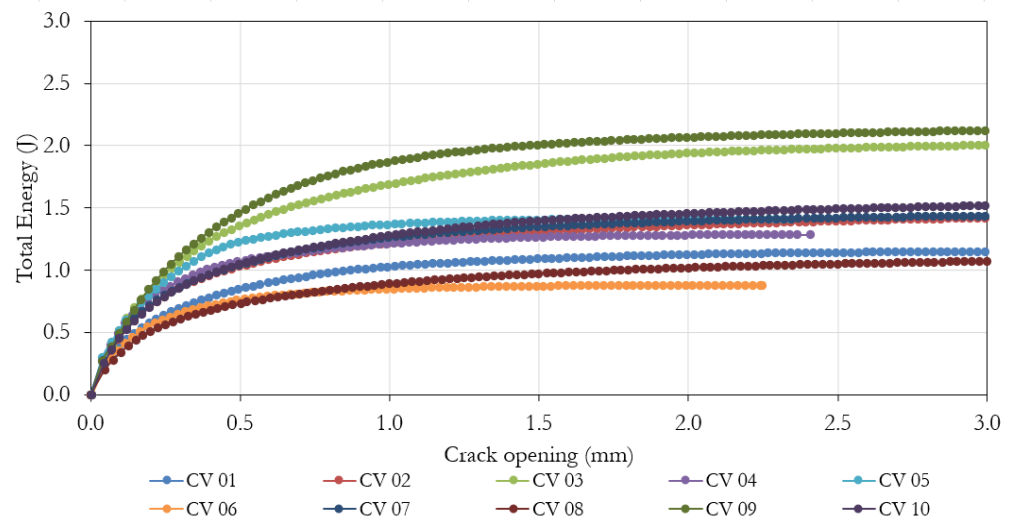

Figure 9. Fracture energy curves for conventional concrete. 


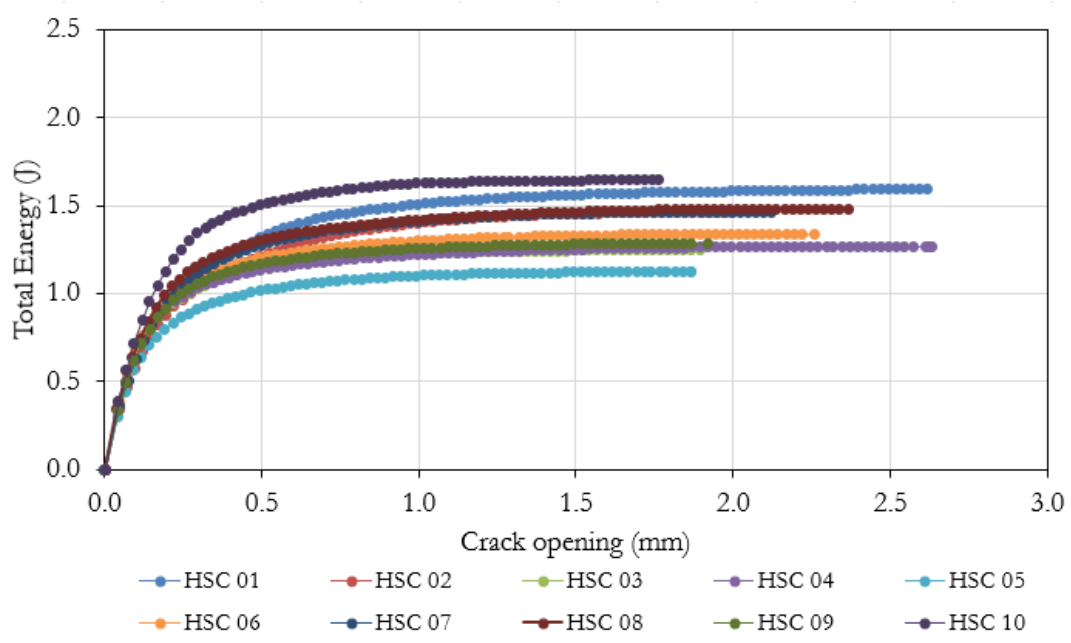

Figure 10. Fracture energy curves for high strength concrete.

The total energy versus crack width curves (Figures 9 and 10), also with absolute values close, show greater dispersion on tests performed with conventional concrete than tests with HSC. During the tests, the conventional concrete presented energy individual values wider than the HSC, in both upper and lower limits.

\section{CRITICAL ANALYSIS OF THE FATIGUE TESTS IN VIEW OF THE FRACTURE TESTS}

Studies conducted by Cervo [12] and Cervo and Balbo [3] resulted in the S-N models for fatigue characterization of the same concretes here assessed regarding their fracture behavior. Figure 11 shows the fatigue test results for both concrete; regarding the conventional concrete, it was evaluated results obtained on 21 concrete beams, which presented standard error of 0.18 and coefficient of determination $\left(\mathrm{R}^{2}\right)$ of 0.91 ; for the HSC, 30 concrete beams were assessed, resulting in a standard error of 0.16 and coefficient of determination $\left(\mathrm{R}^{2}\right)$ of 0.96 . The results also show that the HSC has lower fatigue performance than conventional concrete, which is described by the correlation logarithmic slopes. Figure 12 presents several concrete specimens after ending the flexural fatigue tests.

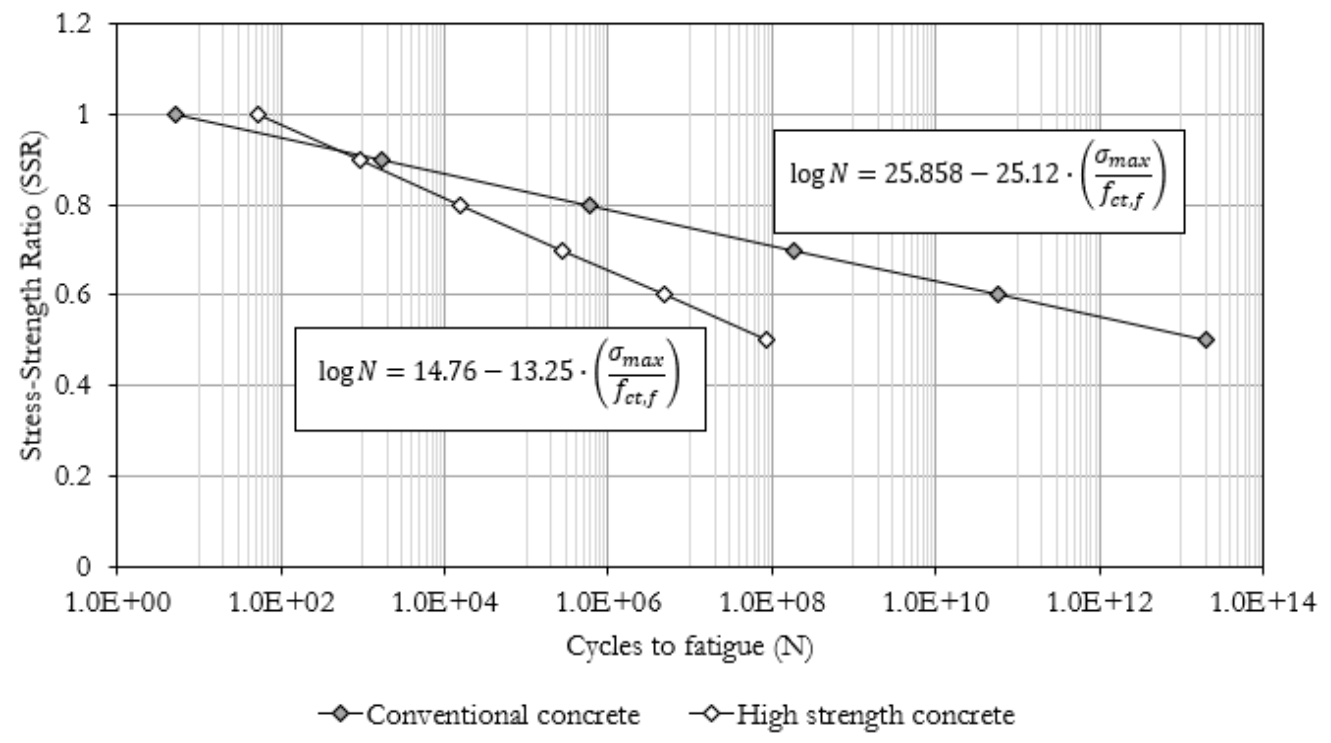

Figure 11. S-N curves for conventional and high strength concrete. 

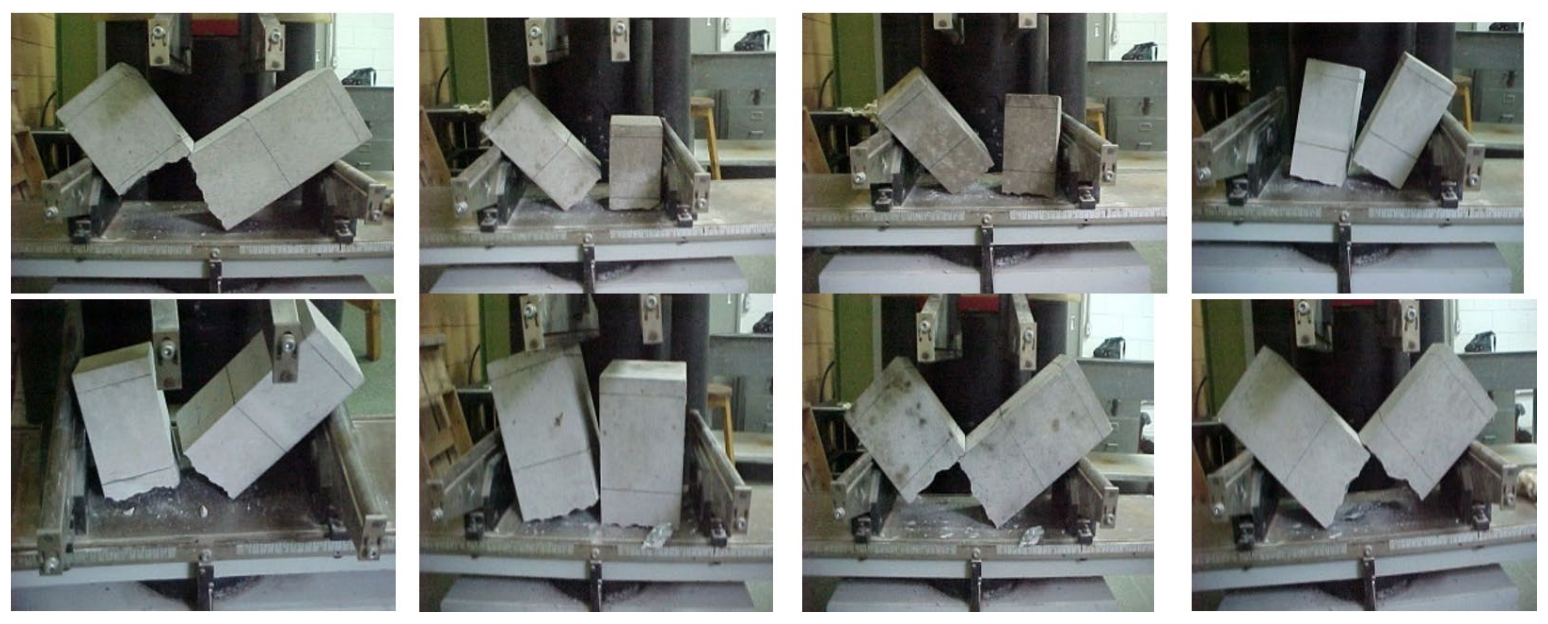

Figure 12. Fractured sections for the high strength concrete during fatigue tests.

It is clearly observed the fatigue rupture rarely happens in the middle third of the span, not even on a specific vertical plan, but on non-flat and usually non-centered surfaces, one of the reasons for the common dispersion of results during tests of such nature. When the specimens are instrumented with LVDT, it is only indicated the vertical strain growth when the fatigue cycle is close to the end. The evident information from the fatigue tests is the HSC smaller capacity to support cyclic loadings compared to a conventional concrete for pavements.

Fracture studies bring new lights to the behavior former recorded, based on fracture parameter determined by tests presented in item 3, as follows. Firstly, in Figure 13 are shown the mean curves force versus crack width for each concrete studied. The overlap of such curves makes clear the energy compensation between curves for $\delta=0.25 \mathrm{~mm}$ and greater than this value. Ignoring the observed discrepancies, the small concrete toughness is very clear in the zones after the peak of the vertical force. The energy dissipation is faster for the HSC (Figure 14), which is greater than conventional concrete until crack width of $1 \mathrm{~mm}$, stabilizing, when there is still some dissipation in the conventional concrete until it breaks, happening when the crack with is twice the HSC crack width.

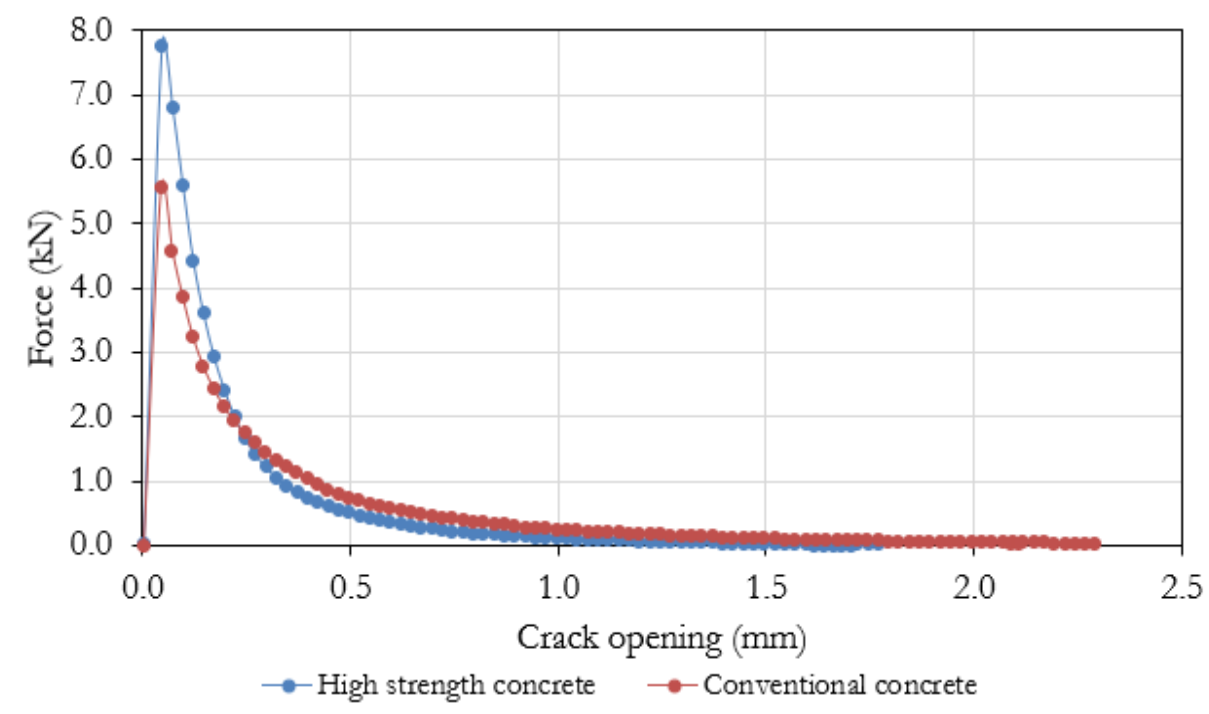

Figure 13. Overlap of the force versus crack width means curves for conventional and HS concrete. 


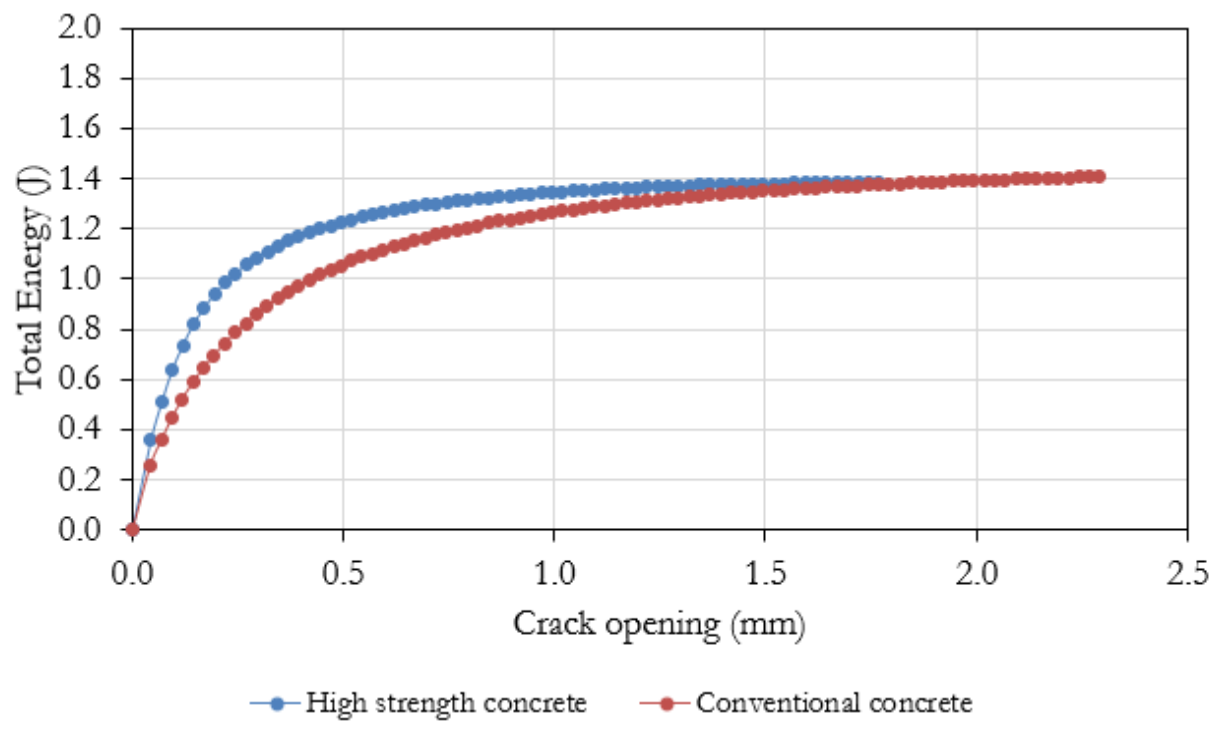

Figure 14. Overlap of the total energy curves along the concrete fracture tests.

In order to compare properties, the concretes compressive strength at 90 days were assessed as $13 \%$ higher than the strength measured at 28 days. Subsequently, the indirect tensile strength was estimated by Equation 7, for values in MPa:

$f_{t}=0.3 \times \sqrt[3]{f_{c}^{2}}$

Tables 3 and 4 show the parameters for tests conducted in individual specimens, as well as the characteristic length $\left(I_{c h}\right)$ results and their brittleness number (B). As seen, the brittleness is reduced for characteristic lengths longer [9], [10], [18], and it is observed from this fracture test numeric parameter that the HSC is weaker than conventional concrete, despite their total fracture energy are similar. In absolute values, the brittleness observed for both concretes, close to each other $(0.24$ and 0.34$)$ are comparable to that of carbon ally refractories [18].

Table 3. Conventional concrete characteristic length and brittleness

\begin{tabular}{cccc}
\hline Specimen & $G_{f}(\mathbf{N} / \mathbf{m m})$ & $I_{c h}(\mathbf{m m})$ & 0.18 \\
\hline CV 01 & 0.000083 & 0.23 & 0.272 \\
\hline CV 02 & 0.000103 & 0.28 & 0.219 \\
\hline CV 03 & 0.000125 & 0.20 & 0.180 \\
\hline CV 04 & 0.000089 & 0.22 & 0.253 \\
\hline CV 05 & 0.000098 & 0.14 & 0.370 \\
\hline CV 06 & 0.000061 & 0.22 & 0.225 \\
\hline CV 07 & 0.000100 & 0.17 & 0.289 \\
\hline CV 08 & 0.000078 & 0.29 & 0.173 \\
\hline CV 09 $10 ~$ & 0.000130 & 0.25 & 0.201 \\
\hline Mean & 0.000112 & 0.22 & 0.241 \\
\hline Standard deviation & 0.000096 & 0.05 & 0.058 \\
\hline Coefficient of variation (\%) & 0.000021 & 21.5 & 24.2 \\
\hline
\end{tabular}

Note: $\mathrm{E}=36.200 \mathrm{MPa} ; f_{t}=4.04 \mathrm{MPa} ; \mathrm{L}=0.05 \mathrm{~mm}$ 
Table 4. High strength concrete characteristic length and brittleness

\begin{tabular}{cccc}
\hline Specimen & $G_{f}(\mathbf{N} / \mathbf{m m})$ & $I_{c h}(\mathbf{m m})$ & $\boldsymbol{B}$ \\
\hline HSC 01 & 0.00011 & 0.17 & 0.301 \\
\hline HSC 02 & 0.00010 & 0.16 & 0.331 \\
\hline HSC 03 & 0.00009 & 0.13 & 0.368 \\
\hline HSC 04 & 0.00009 & 0.13 & 0.368 \\
\hline HSC 05 & 0.00008 & 0.12 & 0.414 \\
\hline HSC 06 07 & 0.00009 & 0.14 & 0.368 \\
\hline HSC 08 & 0.00010 & 0.16 & 0.331 \\
\hline HSC 09 & 0.00010 & 0.16 & 0.331 \\
\hline HSC 10 & 0.00009 & 0.13 & 0.368 \\
\hline Mean & 0.00015 & 0.17 & 0.221 \\
\hline Standard deviation & 0.000100 & 0.15 & 0.340 \\
\hline Coefficient of variation $(\%)$ & 0.000019 & 0.02 & 0.052 \\
\hline
\end{tabular}

Note: $\mathrm{E}=42,900 \mathrm{MPa} ; f_{t}=5.33 \mathrm{MPa} ; \mathrm{L}=0.05 \mathrm{~mm}$

Hypothesis tests (T-test) for paired samples (data set for CV and HSC) were held in order to analyze the numeric parameters obtained for $G_{f}, I_{c h}$ e $B$, for a confidence level of $95 \%$, point out in the following important comments. In the fracture energy test, the hypothesis of equality between the average samples was confirmed, with stat- $t$ equal to 0.245 and $t$-critical for the two-tailed test equal to 2.262, showing stat- $t$ between the limits of the test. However, regarding the critical length, the null hypothesis for the samples is rejected, indicating the mean values are different, with stat- $t$ equal to 4.048 and $t$-critical for the two-tailed test equal to 2.262 . The same trend is observed for the brittleness number, with the rejection of the null hypothesis, i.e., the samples mean values are different, with stat- $t$ equal to -4.22 and $t$-critical equal to 2.262 for the two-tailed test.

From the concrete tensile strengths, calculated as previously described, it is possible to determine the bilinear graphic model [13] to describe and compare the mechanical parameters for both concretes. The draft of the bilinear model after peak requires the following parameters:

- The abscissa of the center of gravity $\left(s_{I}\right)$ of the first triangle as $s_{l}=f_{t} / 3$

- The abscissa of the first interception in the crack opening (displacement) $w_{l}=0.8 G_{f} / f_{t}$

- The abscissa of the second interception in the crack opening (displacement) $w_{l}=3.6 G_{f} f f_{t}$.

Figure 15 represents the bilinear models for both conventional and HSC. The models allow clearly see the fracture parameter of such concretes: comparable fracture energy; stress peak higher in the HSC; fracture rate higher for the HSC; and fracture strain smaller for the HSC.

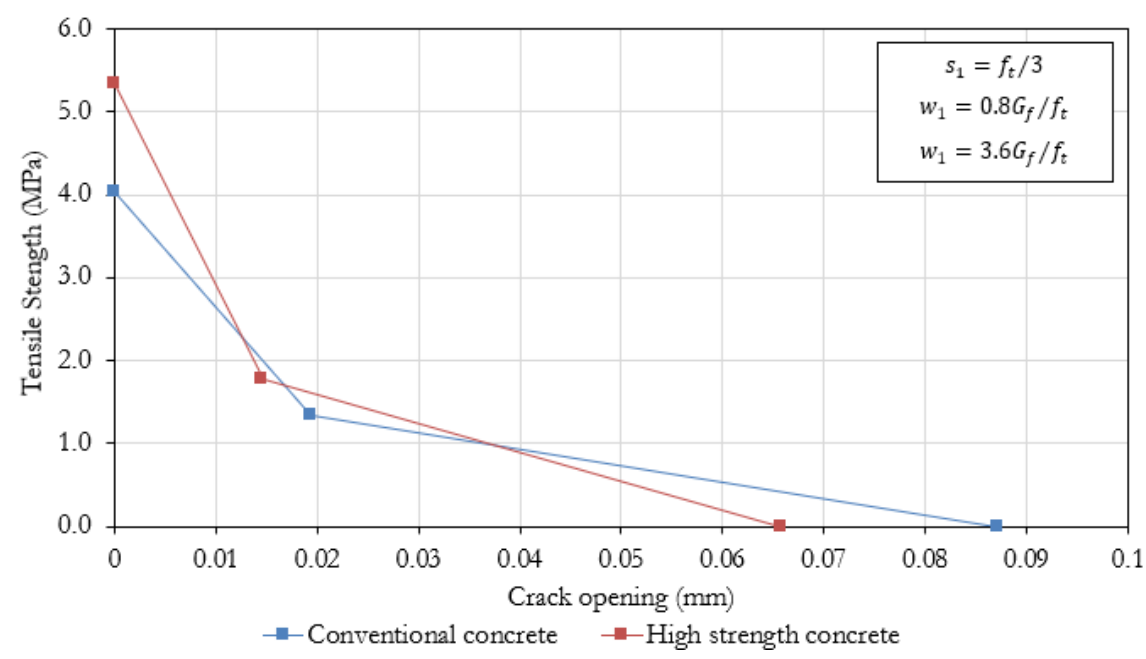

Figure 15. Fracture bilinear mean model for conventional and high strength concrete. 
Taking up the fatigue models obtained for the conventional and HSC, it can be said that the answer on the lower fatigue strength capacity to dynamic and monotonic loading (stress-controlled) is not established based on the specific fracture energy Gf. Fatigue is a process of micro-cracking coalescence in the concrete microstructure, and in the case of HSC the rupture happens faster due to its greater brittleness, which presents characteristic length shorter than conventional concrete. So, the faster cracking coalescence combined to the slower strain levels required for the same coalescence justify the HSC's poor performance regarding the fatigue process, which is a typical process of strain increasing until cracks reach a critical length, resulting in a catastrophic rupture.

Therefore, the fracture tests are excellent to explain the microstructural cracking phenomenon considering the clarification and better understanding of the HSC smaller strength compared to conventional concrete. However, unlike an S-N model, the fracture tests, although based on linear fracture, still do not allow to establish directly cause-effect relationships which could simply allow structural evaluations related to the geometry and strength of concrete slabs for pavements.

\section{CONCLUSIONS}

The fracture tests with two typical concrete for pavement allow summarizing the main findings as follows:

- The high strength concrete (HSC), despite its modulus of elasticity and tensile strength higher than conventional concrete, presented specific fracture energy similar to the conventional concrete, which does not allow singly to distinguish them. Thus, the performed fracture tests do not have enough potential for distinction for the studied cases;

- Otherwise, the critical length and brittleness number were well distinguished by the fracture studies, indicating that such parameters calculated by the described tests (fracture and modulus of elasticity) are good indicators for the desired comparisons;

- The HSC presents rupture strains significantly lower than conventional concrete, which is associated with the HSC highest relaxation rate;

- The HSC has a characteristic length markedly shorter than the conventional concrete, highlighting its brittleness in numeric and objective terms, explaining its worse fatigue behavior;

- What the fatigue tests were not capable to explain from the microstructure point of view and why the HSC fatigue strength is slower than the conventional concrete is well explained by the fracture parameters: the high-performance concrete presented poorer fracture and fatigue performance than conventional concrete for pavements regarding the microstructural indexes and observed parameters.

The future connection between both kinds of test results may allow distinguishing clearer the concretes with different mixing designs as a way of selection for pavement concretes regarding performance criteria much more realistic than the strength tests commonly used as a reference for pavement projects. It is evident the importance of the concrete modulus of elasticity control for the advancement in the mixing design and technologic control criteria since without this parameter would not be possible to discuss tests and conclusions previously addressed.

However, fracture tests alone, considering the current state of the knowledge about mechanistic models for the analysis of concrete pavements structure degradation, whether road, airport or port, do not provide yet elements capable to directly relating the cause and effect of immediate application in daily projects; those tests are not even standardized or specified for studies in this field of knowledge, as a non-encouraging aspect. Nevertheless, the fracture parameters allow an understanding of the microstructural behavior which fatigue tests alone do not provide to the designer/technologist.

\section{ACKNOWLEDGEMENTS}

The authors thank to Dr. Maher Badawy by the support on tests and their interpretation in the Technische Forchungs und Beratungstelle der Schweizer Zement Industry facilities, TFB, Wildegg, Switzerland.

\section{REFERENCES}

[1] P. Wu, "Cement stabilized materials with use of RoadCem Additives," Ph.D. dissertation, Civ. Eng. Dept., Delft Univ. Technol., Delft, 2015.

[2] J. T. Balbo, Personal communication: $i$ was member of this doctoral board and witnessed the questioning, which is very common for technologists who ignore the theoretical, empirical and practical aspects of the pavement mechanics regarding the fatigue degradation of such structures. Delft Univ. Technol., 2015. 
[3] T. C. Cervo and J. T. Balbo, "Calibration of a shift-factor for the fatigue prediction of high strength concrete pavement in the field," Int. J. Pavement Res. Technol., vol. 5, no. 3, pp. 153-160, 2012.

[4] B. L. Karihaloo, H. M. Abdalla, and T. Imjai, "A simple method for determining the true specific fracture energy of concrete," Mag. Concr. Res., vol. 55, no. 5, pp. 471-481, 2003.

[5] RILEM, "Determination of the fracture energy of mortar and concrete by means of three-point bend on notched beams," Mater. Struct., vol. 18, no. 6, pp. 285-290, 1985.

[6] A. Carpentieri and G. A. Ferro, "Scalling behaviour and dual renormalization of experimental tensile softening responses," Mater. Struct., vol. 31, no. 209, pp. 303-309, 1996.

[7] M. Elices, G. V. Guinea, J. Gómez, and J. Planas, "The cohesive zone model: advantages, limitations and challenges," Eng. Fract. Mech., vol. 69, no. 2, pp. 137-163, 2002.

[8] J. G. Rots, P. Nauta, G. M. A. Kusters, and J. Blaauwendraad, "Smeared crack approach and fracture localization in concrete," Heron, vol. 30, no. 1, 1985.

[9] H. Harmuth and R. C. Bradt, "Investigation of refractory brittleness by fracture mechanical and fractographic methods," Interceram, pp. 6-10, 2010.

[10] D. P. H. Hasselman, "Unified theory of thermal shock fracture initiation and crack propagation in brittle ceramics," J. Am. Ceram. Soc., vol. 52, no. 11, pp. 3600-3604, 1969.

[11] Z. P. Bazant and M. T. Kazemi, "Determination of fracture energy, process zone length and brittleness number from size effect, with application to rock and concrete," Int. J. Fract., vol. 44, no. 2, pp. 111-131, 1990.

[12] T. C. Cervo, "Study of fatigue strength of Portland cement concrete for paving," Ph.D. dissertation, Esc. Politec., Univ. São Paulo, 2004.

[13] P. Petersson, "Crack growth and development of fracture zones in plain concrete and similar materials," Rep. TVBM, vol. 1006, pp. 174, 1981.

[14] J. T. Balbo, Pavimentos de Concreto. São Paulo: Oficina de Textos, 2009.

[15] K. Tschegg, M. Elser, and S. E. Stanzl-Tschegg, "Biaxial fracture tests on concrete - development and experience," Cement Concr. Compos., vol. 17, no. 1, pp. 57-75, 1995.

[16] J. T. Balbo, "Estudo das propriedades mecânicas das misturas de brita e cimento e sua aplicação aos pavimentos semirrígidos," Ph.D. dissertation, Dep. Eng. Transp., Esc. Politec., Univ. São Paulo, 1993.

[17] T. Noguchi, F. Tomosawa, K. M. Nemati, B. M. Chaia, and A. P. Fantilli, "A practical equation for elastic modulus of concrete," ACI Struct. J. Title, vol. 64, no. 106-S, pp. 690-696, 2009.

[18] H. Harmuth and E. K. Tschegg, "A fracture mechanics approach for the development of refractory materials with reduced brittleness," Fatigue Fract. Eng. Mater. Struct., vol. 20, no. 11, pp. 1585-1603, 1997.

Author contributions: JTB: writing, conceptualization, formal analysis; modeling; literature review; AAS: testing runner, data acquisition; TCC: testing runner, data acquisition; APC: statistical analysis, writing.

Editors: Osvaldo Luís Manzoli, José Luiz Antunes de Oliveira e Sousa, Guilherme Aris Parsekian. 